\title{
Jóvenes, multitud y estallido social en Chile
}

\author{
Guillermo Rivera-Aguilera, Ph.D. ${ }^{a}$ \\ Pontificia Universidad Católica de Valparaíso, Chile \\ Miguel Imas, Ph.D. ${ }^{b}$ \\ London School of Economics \& Political Science, Gran Bretaña \\ Luis Jiménez-Díaz, Ph.D. ${ }^{c}$ \\ Pontificia Universidad Católica de Valparaíso, Chile
}

guillermo.rivera@pucv.cl

\section{Resumen (analítico)}

El 18 de octubre de 2019, miles de jóvenes chilenos salieron a las calles para exigir una sociedad más justa, iniciando un proceso de cambio constitucional y de ciudadanía. Este artículo analiza ese proceso centrándose en las estrategias disruptivas de los y las jóvenes para impugnar los espacios públicos en los primeros meses de protesta. Con esta finalidad, se realizó una etnografía durante diez semanas _octubre a diciembre del 2019_-, en las ciudades de Santiago y Valparaíso. Los resultados muestran que estos jóvenes se identifican como parte de una multitud que ha experimentado un despertar ciudadano, exigiendo mayor participación social. Se concluye que este despertar refleja las tendencias sociales de las juventudes de otras partes del mundo, que igualmente disputan y exigen transformaciones sociales en las democracias liberales.

\section{Palabras clave}

Conflicto social, movimiento de protesta, movimiento juvenil.

\section{Thesauro}

Tesauro de Ciencias Sociales de la Unesco.

\section{Para citar este artículo}

Rivera-Aguilera, G., Imas, M., \& Jiménez-Díaz, L. (2021). Jóvenes, multitud y estallido social en Chile. Revista Latinoamericana de Ciencias Sociales, Niñez y Juventud, 19(2), 1-23.

https://dx.doi.org/10.11600/rlcsnj.19.2.4543

\section{Historial}

Recibido: 28.09.2020

Aceptado: 23.11.2020

Publicado: 30.04 .2021

\section{Información artículo}

El artículo corresponde a un estudio etnográfico (finalizado) que es parte de un proyecto mayor de tres años de duración (2018-2020), cuyo objetivo es analizar, a través de tres estudios cualitativos interrelacionados, cómo se gobierna a la juventud vulnerable en Chile. El estudio etnográfico se realizó entre el 20 de octubre del 2019 y el 27 de diciembre del 2019. Financiación: Proyecto Fondecyt n. ${ }^{\circ}$ 3180338 del Fondo Nacional de Desarrollo de la Ciencia y la Tecnología, Chile. Sociología: Juventud. Área: sociología. Subárea: sociología. 


\section{Youth, multitudes and social upheaval in Chile}

\section{Abstract (analytical)}

On October 18, 2019 in Chile, thousands of young people flooded the streets to demand a fairer life, representing the start of the construction of a new citizenship. This article analyzes how these young people disputed the control of public spaces in the first months of this social upheaval. An ethnography was carried out for ten weeks between October and December 2019 in the cities of Santiago and Valparaíso, observing and interviewing mobilized young people. The results show that the young people protesting in in the street identify themselves as being part of a social awakening. The Chilean case is discussed as part of a synergy of youth revolts at a global level. The authors conclude that the young people who protest belong to a generation that questions liberal democracies as the dominant form of participation and political action.

Keywords

Social conflict, protest movement, youth movement.

\section{Jovens, multidões e explosão social no Chile}

\section{Resumo (analítico)}

Em 18 de outubro de 2019 no Chile, milhares de jovens sitiaram as ruas para exigir uma vida mais justa, começando a construir uma nova cidadania. Este artigo analisa como esses jovens disputaram os espaços públicos nos primeiros meses da 'revolta social'. Foi realizada uma etnografia durante dez semanas - outubro e dezembro de 2019 - nas cidades de Santiago e Valparaíso, observando e entrevistando jovens mobilizados. Os resultados mostram que esses jovens constituem uma multidão nas ruas que os identifica com um despertar social. O caso chileno é discutido como parte de uma sinergia de revoltas juvenis em nível global, e conclui-se que os jovens que protestam pertencem a uma geração que questiona as democracias liberais como forma de participação e ação política.

Palavras-chave

Conflito social, movimento de protesto, movimento juvenil.

\section{Información autores}

[a] Dr. en Psicología, Pontificia Universidad Católica de Valparaíso, Chile. Profesor asociado de la Pontificia Universidad Católica de Valparaíso, Chile. (iD) 0000-0002-2724-481X. H5: 5. Correo electrónico: guillermo.rivera@pucv.cl

[b] Ph.D. Social Psychology, London School of Economics \& Political Science. (iD) 000-0003-2947-8086. H5: 6. Correo electrónico: j.imas@kingston.ac.uk

[c] Dr. en Psicología, Pontificia Universidad Católica de Valparaíso, Chile. Profesor agregado de la Pontificia Universidad Católica de Valparaíso, Chile. (iD 0000-0001-6739-5586. H5: 1. Correo electrónico:

luis.jimenez@pucv.cl 


\section{Introducción}

Nos quitaron tanto, que nos quitaron hasta el miedo.

-Protestante anónimo

$\mathrm{C}_{\text {de Santiago fueron invadidas por manifestantes que, a través de la protesta social, }}^{1}$ demandaron un sistema económico más equitativo y llamaron a poner fin al neoliberalismo como forma de gobierno (Frías \& Garcés, 2019; Rivera-Aguilera \& Jiménez-Díaz, 2020). Jóvenes estudiantes iniciaron las movilizaciones con la mundialmente conocida evasión del Metro ${ }^{1}$ en Santiago, manifestándose en contra del alza de tarifas. Lo que comenzó con un llamado a evadir, desató la indignación social que gatilló la consigna «Chile despertó».

La revuelta social chilena se suma a otros procesos vividos en Latinoamérica desde los comienzos del nuevo milenio. Estos procesos se han caracterizado por ser movimientos colectivos, basados en demandas puntuales y que usan la protesta como método de acción que cuestiona principalmente al neoliberalismo (Fry, 2020). Unos de los actores que ha tomado protagonismo en estas revueltas han sido las juventudes. Por ejemplo, en países como Argentina, Brasil, Colombia y México se observan que las manifestaciones juveniles se caracterizan por ser protestas directas, basadas en acciones colectivas y en formas artísticas de movilización social (Vommaro, 2016, 2017). Las juventudes producen movimientos de ruptura a los modelos políticos porque no les representan y les marginan. En este escenario, las revueltas juveniles latinoamericanas del siglo XXI han mostrado una característica particular: la dicotomía de la protesta directa (Vommaro, 2016), que es la paradoja entre la instalación de demandas desde jóvenes en los espacios públicos con una búsqueda constante de diálogos con el Estado.

\footnotetext{
${ }^{1}$ Tren subterráneo.
} 
El estallido social chileno se gestó por jóvenes que aprendieron formas de acción políticas de las manifestaciones estudiantiles iniciadas el 2006, donde se configuró un movimiento diverso en clases sociales, grupos generacionales y niveles educacionales (Rozas-Bugueño \& Somma, 2020). Esto, sumado al triunfo de un gobierno representado por partidos políticos de derecha, contribuyó a la formación de un movimiento juvenil marcado por una sensación crónica de frustración, con una profunda indignación hacia la política. De esta forma, el estallido social iniciado el 18 de octubre de 2019 se configura como una protesta que buscó el pensar, desde la calle y en los espacios públicos, nuevas formas de construir ciudadanía (Faure, 2020).

En relación a lo expuesto, en este artículo nos preguntamos: ¿cómo los y las jóvenes disputan el espacio público a través de la protesta social? Desde esta interrogante, a lo largo de este estudio analizamos las revueltas juveniles como posibilidad para repensar un orden político, económico y social impuesto por la ideología neoliberal.

El texto está estructurado de la siguiente manera: primero, planteamos algunos antecedentes sobre el estallido social chileno y conceptualizaciones sobre lo que entendemos por juventudes que protestan. Segundo, tomando como referencia la categoría de multitud (Hardt \& Negri, 2011, 2012; Virno, 2003), abordamos la indignación y la revuelta social como elementos de análisis. Tercero, a partir de un trabajo etnográfico (Foley \& Valenzuela, 2012), ilustramos cómo las juventudes chilenas disputan los espacios públicos y cómo narran las causas y motivaciones de sus acciones. Finalmente, discutimos cómo el caso chileno se puede entender como parte de una sinergia de revueltas juveniles ocurridas a nivel global.

\section{Juventudes, protestas y estallido social}

Desde el año 2000 - y a nivel mundial - se han observado una serie de revueltas sociales protagonizadas por jóvenes. Algunos ejemplos son la revolución cultural en Marruecos (Sánchez-García \& Touhtou, 2021); las voces de la calle definidas por Bartra (2014), respecto de las manifestaciones de jóvenes en Nueva York que cuestionaron el mercado de Wall Street en 2011; la huelga estudiantil contra el aumento de pago de matrículas en Quebec en 2012; y las protestas de jóvenes en Turquía contra el desarrollo urbano en Estambul en 2013, por mencionar algunas.

En este escenario, es evidente la relación entre las iniciativas ciudadanas por cambios en los modelos políticos, donde las revueltas sociales y las nuevas generaciones han configurado el concepto de juventud activista (Soler-i-Martí et al., 2021) que se constituye 
desde su composición heterogénea. En el caso de España, los estudios de Soler-i-Martí et al. (2021) y Tejerina (2019) identifican un patrón en la disparidad de jóvenes pues, a pesar de su diversidad, comparten el concepto de periferia que se materializa en la subalternidad y en la idea de precariedad. De esto derivan sentimientos de vivir en una sociedad a la que no pertenecen, situándose conscientemente en la marginalidad del espacio social y desconfiando de la institucionalidad, lo que implica organizarse desde la periferia.

Latinoamérica vivencia una situación similar, pues históricamente y tras el posicionamiento del neoliberalismo, las juventudes, más allá de su heterogeneidad, comenzaron a compartir sentimientos de desigualdad, generalizando el descontento frente a los procesos de inclusión desarrollado por las políticas públicas que, tal como señalan Fry (2020) y Vommaro (2016) se sustentan en una inclusión-excluyente. Bajo estos preceptos, las juventudes activistas son definibles como jóvenes en la calle, porque se constituyen como una generación de ruptura que comparte una perspectiva sociohistórica porque poseen experiencias vitales y experimentan problemas comunes, a pesar de su carácter diverso (Ganter-Solís \& Zarzuri-Cortés, 2020; Vommaro, 2017).

En el caso chileno, estas experiencias comunes convocaron a miles de jóvenes a reclamar una vida diferente y, al igual que en otros países de Latinoamérica, gatillaron otras demandas ciudadanas que produjeron distintas acciones gubernamentales para resolverlas (Ganter-Solís \& Zarzuri-Cortés, 2020; Vommaro, 2016). No obstante, el estallido social de 2019 adquirió características peculiares. Días antes del 18 de octubre, cuando las y los jóvenes secundarios se movilizaron por el alza del pasaje del Metro bajo la consigna «evade», construyeron un enunciado que marcó un punto de inflexión. Ya no se convocaba a un grupo específico, sino a un sujeto individual, anónimo, sin género, bajo el llamado a romper la norma. A partir del hecho específico de la evasión del pago en el transporte público se abría un abanico de posibilidades y demandas al modelo político, económico y social (Campos-Medina, 2020).

Desde el 18 de octubre de 2019 en adelante, las y los jóvenes salieron multitudinariamente a las calles en diferentes ciudades de Chile, no a exigir cambios puntuales ni a propiciar diálogos con el Estado, sino a generar, a través de su autoorganización, promover una nueva ciudadanía (Campos-Medina, 2020; Faure, 2020; Ganter-Solís \& ZarzuriCortés, 2020). La calle fue el lugar elegido para manifestar, no solo su rechazo al alza del transporte, sino también su descontento con la democracia neoliberal (Frías \& Garcés, 2019). Además, se hicieron presentes diversas demandas juveniles acompañadas por banderas del pueblo Mapuche, evidenciando los abusos sistemáticos a los pueblos originarios, 
así como las denuncias a la mercantilización de la educación. Estas acciones articularon un malestar acumulado que vio en el espacio público el lugar apropiado para la protesta social. Con el paso de los días, dicho espacio permitió aunar nuevos descontentos y una diversidad de jóvenes: escolares, universitarios, indígenas, migrantes, desempleados y precarizados. Debido a esto, Salazar (2019) define al estallido social como la chispa que despertó a la ciudadanía marginada, porque emergió una masa popular compuesta y articulada por jóvenes que tienen una memoria de rabia y de exclusión. No solo intervinieron las calles pacíficamente, sino también ocuparon la ciudad con saqueos y violencia, dado que se involucraron grupos periféricos y excluidos socialmente.

Las consecuencias del estallido social llevaron a las autoridades políticas —de manera inmediata-, a utilizar la estrategia de criminalizar la protesta bajo la premisa histórica que las fuerzas policiales y militares son un dispositivo indispensable para la paz y el orden público (Beyer, 2019; Jiménez-Díaz, 2018, 2019; Rivera-Aguilera et al., 2016). Así, el 20 de octubre, tras decretar Estado de Emergencia, el presidente Piñera declaró en cadena nacional, que «estamos en guerra contra un enemigo poderoso que no respeta a nada ni a nadie», enfatizando que los manifestantes provenían de círculos subversivos organizados, por lo que era indispensable la presencia militar y el toque de queda (Andrews, 2019; ¿Qué implica que el gobierno de Chile declare estado de emergencia?, 2019). Tales medidas hicieron recordar los oscuros años de la dictadura militar a millones de chilenos y chilenas.

Si bien el miedo se hizo presente, estas medidas no lograron el efecto esperado. Muy por el contrario, miles de personas se agruparon diariamente en las calles, convocando a marchas, manifestaciones y llamando al desorden público. En el centro de Santiago, la Plaza Italia (que es un lugar de encuentro asociado a la celebración de triunfos deportivos, electorales y otros) en el contexto del estallido social no solo fue sitiada, sino también rebautizada con el emblemático nombre de Plaza de la Dignidad (De «Plaza Italia» a «Plaza de la Dignidad», 2019). El punto cumbre de la manifestación ciudadana se produjo el viernes 25 de octubre, en la denominada «marcha más grande de Chile», que congregó en Santiago a más de 1.2 millones de personas en esa plaza, configurando un evento sin precedentes (Valenzuela, 2019). Las manifestaciones se extendieron a lo largo del país y se caracterizaron por prácticas propias de la resistencia frente a la dictadura, tales como el cacerolazo, el rayado de muros, así como consignas sobre el respeto a la dignidad y los derechos humanos. También se realizaron una serie de iniciativas que apuntaban al fortalecimiento de la participación ciudadana, tales como cabildos territoriales, 
asambleas, talleres, encuentros y conversatorios, donde la ciudadanía buscó la autonomía como forma de gestión y organización (Martuccelli, 2019).

\section{Indignación y rebelión}

A lo largo de la historia y en distintas culturas las acciones de rebelión y revueltas tienen en común el hecho que representan antagonismos donde se agrupan y conforman colectivos u otras formas de organización para ejercer presión sobre los poderes dominantes. Siguiendo a Hardt y Negri (2011), lo que articula estas formas de protesta y rebelión es la indignación. Para argumentarlo toman como referencia a Spinoza, entendiendo que la indignación genera efectos y acciones que se manifiestan desde prácticas antagonistas que los individuos llevan a cabo frente a la negación de libertad, a las injusticias del poder y al control social extremo. En términos concretos:

En la expresión de indignación nuestra existencia misma se rebela. De esta suerte, la indignación incluye una cierta cantidad de violencia. Esto atañe estrechamente al hecho que mencionábamos anteriormente, de que la resistencia al poder, la expresión de libertad contra la violencia del poder, implica siempre una dimensión de fuerza. (Hardt \& Negri, 2011, p. 243)

En el caso chileno, hemos reconocido que es la indignación lo que hace a salir a la calle a los y las jóvenes a tomarse los espacios públicos. En otras palabras, se genera una conciencia en que es el propio cuerpo el que puede actuar y decir algo en contra de un modelo desde una posición antagonista, que se materializa en una rebelión contra el capital y el modelo económico que representa. Tal como ilustramos más adelante, el deseo de salir a manifestarse por parte de los y las jóvenes emerge como producto de una sensación de injusticia, sufrimiento y rabia, tanto individual como colectiva.

\section{La multitud}

¿Cómo referirse a los millones de personas que salen a las calles de Santiago el 25 de octubre de 2019?, ¿corresponden a un movimiento social, son el pueblo, son los precarios o los indignados? No es fácil categorizar en un concepto este gran cuerpo social que marca un hito histórico en Chile, puesto que la diversidad de personas que salió a la calle, unidas en un solo cuerpo, abarca un sinfín de subjetividades antagónicas.

El concepto de multitud desarrollado por Hardt y Negri (2011), así como por Virno (2003), tuvo una fuerte influencia en la filosofía política al inicio de la presente década. 
Toma como referencia la idea de Hobbes que los ciudadanos cuando se rebelan contra el Estado representan la multitud (Virno, 2003). Con este constructo se hace referencia a un actor social activo, a una multiplicidad singular; es decir, a una multiplicidad que actúa, que se distancia de categorías como el pueblo, asociado a una unidad concreta o a un grupo social más específico. Desde esta perspectiva, para este estudio entendemos la multitud como un conjunto de singularidades que salen a la calle a manifestarse como una agente social activo y autoorganizado (Hardt \& Negri, 2012; Martínez \& Barragán, 2008). También entendemos la multitud como cybercuerpos que se mueven libremente en espacios virtuales y conectan lo humano con lo no humano.

Siguiendo a Papadopoulos (2018), estos nuevos entendimientos asociados a una ontología distinta de los movimientos sociales constituyen nuevas subjetividades que ensamblan nuevos lenguajes y nuevas luchas contra el capital, así como una ética diferente que constituye la vida social de nuestros días. Por esto, en este estudio entendemos a los y las jóvenes como una nueva subjetividad antagónica que, a través de sus movimientos y articulaciones, obedece al engranaje de la multitud. Tal como han señalado Martínez y Barragán (2008), las acciones juveniles se tornan multitud cuando se apropian del espacio y, en esos movimientos, se constituyen en sujetos activos y libres, encarnando una nueva subjetividad política.

\section{Jóvenes alteractivistas y una generación sin miedo}

Si bien Pleyers (2018) no se refiere directamente a las juventudes, las posiciona como parte importante de los movimientos sociales del siglo XXI, afirmando que la idea de transformar el mundo se ha desplazado hacia una cultura particular que denomina «alteractivistas», ${ }^{2}$ conformada por quienes rechazan los modelos dominantes configurados por estructuras básicas de la sociedad civil. Las formas de alteractivismo se expresan tanto en el espacio público como en la vida cotidiana, abarcando elementos como el modo de pensar, de vestir, de entender una sexualidad diversa, así como las formas de relación con otros y otras. Así, el compromiso político no se limita a lo que tradicionalmente se define como lo político; por el contrario, los alteractivistas actúan de acuerdo a sus valores tanto en las protestas como también en su vida cotidiana, por ejemplo, en las maneras de acceder al consumo, en respuesta al dilema de comprar o no comprar. Para el caso chileno, diferentes autores vinculan lo anteriormente planteado con la definición de una

\footnotetext{
${ }^{2}$ Es importante dejar en claro que la categoría alteractivista no corresponde a una identidad colectiva en particular, ni tampoco un término utilizado por los propios actores.
} 
generación sin miedo (Esteve, 2019; Sandoval \& Carvallo, 2019). La cual se caracteriza por una posición crítica frente la democracia actual por considerarla segregadora, ilegítima, vinculada al neoliberalismo y sustentada en una lógica policial (Sandoval \& Carvallo, 2019). Estas nuevas generaciones no temen a la represión, porque se asumen desde la exclusión. Tampoco temen a la carencia de liderazgos claros, porque desde sus prácticas son capaces de construir nuevas formas de ciudadanía (Esteve, 2019; Sandoval \& Carvallo, 2019).

\section{Método}

Este estudio forma parte de una investigación más amplia ${ }^{3}$ que se desarrolló entre 2018 y 2020, con la finalidad de analizar cómo se gobierna a la juventud vulnerable en Chile, a través de tres estudios cualitativos interrelacionados. En este artículo presentamos los resultados correspondientes a un estudio etnográfico que no estaba planificado en el proyecto inicial sino que fue incorporado posteriormente, producto de los acontecimientos ocurridos en Chile a partir del 18 de octubre de 2019 .

La metodología utilizada es de carácter cualitativo, basada en tradiciones epistemológicas que se sustentan en discursos y prácticas que permiten comprender la construcción de la realidad desde la perspectiva de los propios actores sociales (Denzin \& Lincoln, 2012). Para esto nos situamos desde la etnográfica crítica (Foley \& Valenzuela, 2012), que toma como referencia elementos de la cuasietnografía (Silva \& Burgos, 2011) y la fotoetnografía (Hermansen \& Fernández-Droguett, 2018). Para este estudio entendemos la etnografía como un enfoque multimetódico que incluye observaciones, participación en espacios públicos, fotografías, registro de conversaciones, análisis de prensa, análisis de convocatorias y talleres (Denzin \& Lincoln, 2012; Eberle \& Maeder, 2016).

Como investigadores nos posicionamos en la etnografía crítica, porque no adherimos al positivismo objetivo de la observación etnográfica clásica y exploramos, desde la reflexibilidad (Alvesson \& Skoldberg, 2018), las interacciones que generan nuestra participación en el campo, pues somos parte de la sociedad observada y salimos a la calle a protestar, al igual que los participantes del estudio. Nuestra posición en el campo buscó generar reflexiones críticas acerca de las dinámicas sociales y las relaciones intersubjetivas entre los y las jóvenes, producto del estallido social. Siguiendo a Denzin y Lincoln (2012), consideramos que la etnografía es política, y más bien, una acción política, particularmente

\footnotetext{
${ }^{3}$ Proyecto Fondecyt n.․ 3180338 del Fondo Nacional de Desarrollo de la Ciencia y la Tecnología, Chile.
} 
en una sociedad como la chilena, marcada por el conflicto de clases, violencia de género e injusticias sociales producto del sistema económico instalado hace ya más de zo años.

Desde este enfoque, y en un contexto de manifestaciones sociales, el espacio urbano está en un constante cambio; ello fue desafiante al momento de encontrar metodologías que, teniendo como referencia el paradigma cualitativo, permitieran conocer las distintas articulaciones que se generan, siendo las calles, plazas y parques espacios para manifestarse. Siguiendo a Hermansen y Fernández-Droguett (2018), la fotoetnografía «permite imbricar las dimensiones ético-política y metodológica-disciplinar de la indagación, mediante la correspondencia entre la investigación fotoetnográfica y los modos y fines de la manifestación política» (p. 178). Es por ello que nuestra posición etnográfica procura dar cuenta de los elementos más sobresalientes o visibles de las manifestaciones y registrar las prácticas que se construyen en las prácticas políticas contemporáneas, poniendo el énfasis en las revueltas juveniles del siglo XXI (Hermansen \& Fernández-Droguett, 2018).

\section{La producción de datos}

La forma de registro incluyó cuadernos de campo, fotografías e instrumentos de grabación de audio. El trabajo se extendió por diez semanas entre los meses de octubre a diciembre del 2019. Cada salida al campo fue realizada en dos centros urbanos, para lo cual se eligió las ciudades de Santiago y Valparaíso. Esto no fue intencionado, ya que los investigadores nos encontrábamos en esas ciudades.

Cada salida al campo se realizó por uno o dos investigadores de nuestro equipo, con una duración de tres a cinco horas. Los días de la semana variaban, pues dependían de las actividades que ocurrían en las ciudades y en el espacio público; por ejemplo: marchas, encuentros callejeros, asambleas ciudadanas, cabildos o encuentros comunitarios. Así, se generó una producción de datos que se resume en la tabla 1.

Durante los primeros meses de las salidas a terreno, se registraron en cuadernos de campo los principales elementos que configuraron las actividades juveniles, estos fueron agrupados en cuatro grandes categorías: 1) la ocupación del espacio público; 2) el rechazo a los símbolos del neoliberalismo en los espacios públicos; 3) la consigna de «Chile despertó» como el nacimiento de una nueva forma de vida social; y 4) actividades ciudadanas y de nuevas formas de hacer política. 


\section{Tabla 1}

Producción de datos

\begin{tabular}{lc}
\hline $\begin{array}{l}\text { Actividades generales } \\
\text { Salidas a marchas y convocatorias ciudadanas }\end{array}$ & 28 \\
\hline Actividades específicas & \\
$\quad$ Talleres con jóvenes universitarios y profesores en la & 1 \\
Pontificia Universidad Católica de Valparaíso & \\
\hline Registro & 28 \\
Registros de campo & 12 \\
Registro de conversaciones con jóvenes manifestantes & 400 \\
Fotografías
\end{tabular}

Los criterios aplicados para seleccionar a los y las participantes de las conversaciones, fueron: 1) ser jóvenes manifestantes en las protestas ciudadanas en Santiago y Valparaíso; 2) tener edades entre los 20 y los 25 años; 3 ) ser estudiantes de educación superior; y 4) ser residentes de las ciudades de Valparaíso y Santiago. El taller realizado con jóvenes estudiantes de la Pontificia Universidad Católica de Valparaíso se realizó bajo los mismos criterios, con el fin de validar los resultados del proceso de recolección de datos.

Las conversaciones con los y las jóvenes fueron estructuradas según las estrategias de la entrevista etnográfica y fundamentadas en los principios de Guber (2005, 2011). Las preguntas fueron elaboradas en virtud de las categorías construidas en los cuadernos de campo. Tras la recopilación de la información y de acuerdo con los principios de saturación y triangulación (Kornblit, 2004) se contrastó los datos de los cuadernos de campo, las entrevistas y las fotografías, lo que permitió configurar el corpus de análisis.

\section{Análisis de la información}

Los datos producidos fueron transcritos por ayudantes de investigación del proyecto y fueron sometidos a un proceso analítico que incluyó una categorización simple. La información fue organizada en matrices analíticas desarrolladas para este estudio, que incorporaron las fotografías y las conversaciones con jóvenes, configurando así la información narrativo-visual.

El análisis de los datos se realizó desde dos ejes: el primero fue descriptivo-espacial, al que denominamos «la disputa por el espacio urbano», que da cuenta del trabajo fotoetnográfico realizado, a través de dos imágenes seleccionadas que exponen los espacios 
de la ciudad en el contexto de estallido social; el segundo eje fue narrativo y lo denominamos «de la multitud al sujeto». Este aborda las subjetividades juveniles, principalmente a partir de registros de conversaciones sostenidas con jóvenes manifestantes durante el trabajo de campo. Estas conversaciones fueron breves en términos de tiempo (entre cinco y diez minutos) y se realizaron en el contexto de las manifestaciones sociales. A partir de los datos de los cuadernos de campo, hicimos tres preguntas a los jóvenes: 1 ) ¿Por qué sales a la calle a protestar?; 2) ¿Por qué crees que Chile despertó?, y 3 ) ¿Qué visualizas como alternativa al modelo existente?

Tomando como referencia los dos ejes propuestos, se profundizaron las formas en que las dimensiones espaciales y narrativas se relacionan entre sí, permitiendo establecer una serie de conexiones y entrecruzamientos asociados a la disputa por los espacios públicos. Finalmente, se discutió sobre cómo estos resultados y este tipo de estudio contribuye al debate sobre las revueltas juveniles y un entendimiento de las multitudes en Chile y Latinoamérica.

\section{Consideraciones éticas}

La identidad de los y las participantes se mantienen en el anonimato, tanto a través de las imágenes como en los fragmentos de las conversaciones sostenidas. Las fotografías seleccionadas no permiten identificar rostros y se determinó no registrar ni almacenar información personal de los y las jóvenes con quienes conversamos. Estas consideraciones éticas descritas fueron informadas al momento de solicitar a las personas su participación en el estudio.

\section{Resultados}

\section{Eje 1: la disputa por el espacio urbano}

El primer eje analítico abordado se centra en la disputa del espacio público que los y las jóvenes reclaman. Esto ocurre en un lugar histórico y simbólico de Santiago: la Plaza Italia/Plaza de la Dignidad. Aquí es donde la ciudad se divide, geográfica y socialmente, entre quienes tienen y quienes aspiran a tener. Es donde se materializa la desigualdad que se busca subvertir a través de la toma simbólica que opera desde el propio cuerpo de las juventudes. En este espacio, reclaman la dignidad que el modelo neoliberal les ha negado. Frente a una sociedad que valora lo monetario por sobre lo social, los y las jóvenes 
manifestantes alzan sus voces en contra del sistema que les priva, oprime y segrega de un futuro con mayor bienestar. La toma de este lugar tan central en Chile simboliza el descontento, que se expresa también mediante la destrucción material de algo tan representativo del modelo neoliberal en Chile: el Metro.

\section{Figura 1}

Alrededores de la Plaza de la Dignidad, Santiago de Chile, 12 de noviembre 2019

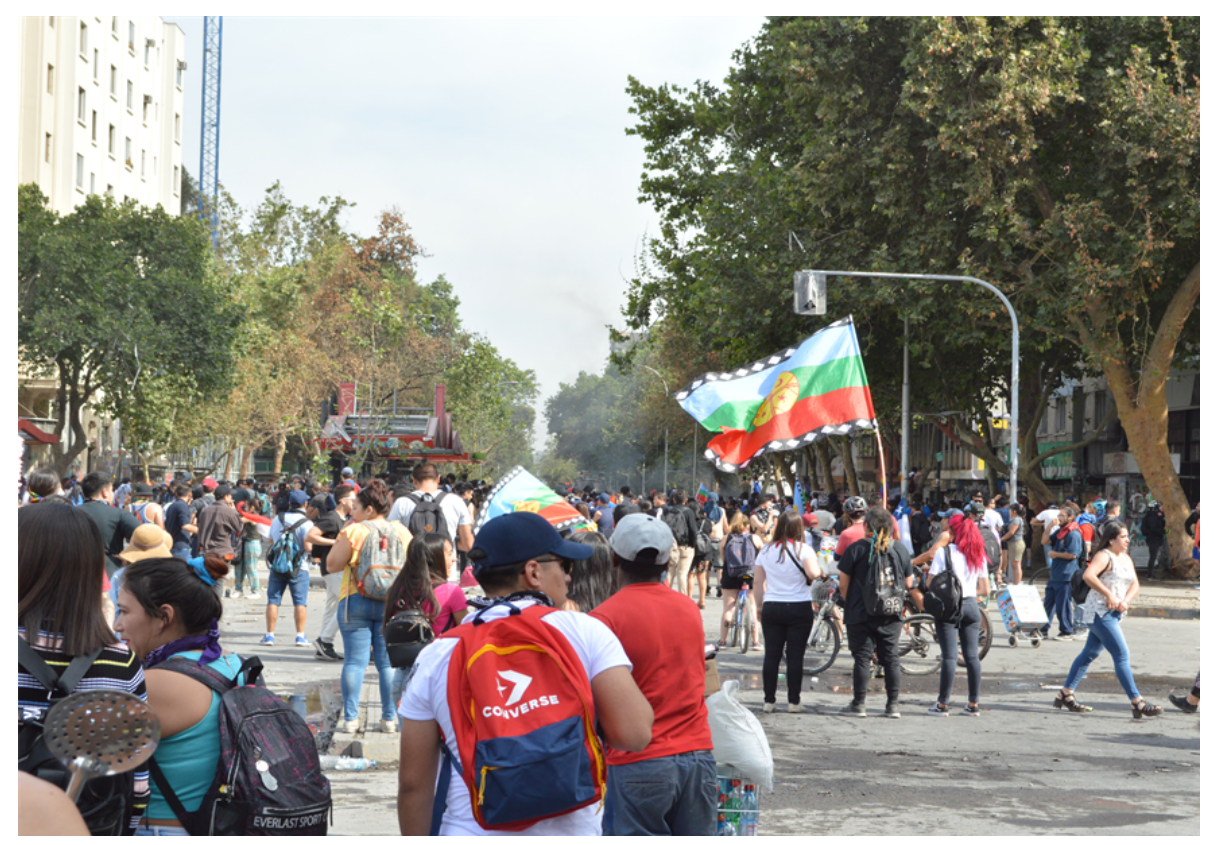

Nota. (c) 2020.

Frente a las promesas del mercado sobre la aspiración de tener todo el derecho a desear, las juventudes sienten que el sistema les miente y los margina. En paralelo, la ausencia de valores de convivencia y participación ciudadana ha conllevado a que los y las jóvenes aspiren, como forma de éxito, a la adquisición de bienes materiales; así, las juventudes desposeídas se sienten engañadas y manifiestan su frustración destruyendo lo que representa la institucionalidad.

La segregación social — propia de los regímenes poscolonialistas-, se contrapone a los discursos de justicia social del retorno a la democracia y genera rabia contra aquello que se significa como colonial. El uso de la bandera mapuche simboliza su rebeldía frente a un modelo político y económico que se interpreta como colonizador. Esta colonialidad se percibe a través del sentimiento de esclavitud frente al futuro, donde los y las jóvenes observan como inevitable el camino del endeudamiento para sustentar sus vidas, 
sin acceso a seguridades y derechos básicos tales como la educación, la vivienda y la salud. De esta forma, emerge la violencia contra los símbolos empresariales del modelo neoliberal, los cuales son plasmados a través de denuncias escritas en las paredes de Santiago (figura 2).

\section{Figura 2}

Local de cadena de farmacia Cruz verde en el centro de Santiago, 14 de noviembre 2019

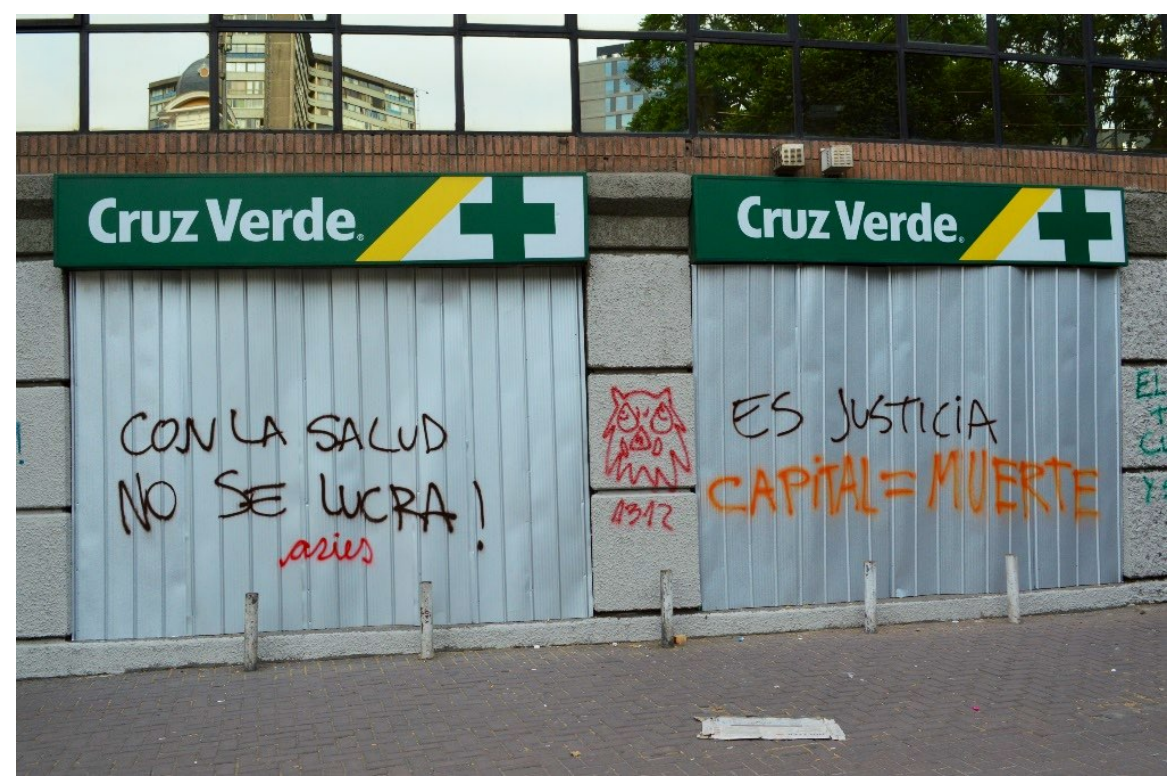

Nota. (c) 2020.

En esta imagen se aprecia el sentir y el malestar de una ciudadanía vulnerada en sus derechos. Corresponde a la fachada de una transnacional farmacéutica, a través de la cual ilustramos la violencia de la protesta social frente a los conglomerados económicos que se enriquecen con la comercialización de la vida. ${ }^{4}$ El enunciado «Con la salud no se lucra» da cuenta del rechazo a los sistemas de salud basados en la riqueza de unos pocos, generando una la lógica de que el capital es igual a la muerte, ya que depara un futuro de miseria y precariedad para los más vulnerables. Para los jóvenes vivir en una sociedad mercantilizada solo favorece la colusión de las empresas, lo que genera indignación y rabia. Sus efectos producen altos costos de la salud en términos de previsiones, atención y medicamentos, no garantizando el cuidado de la vida. En este sentido, rechazan que el costo de la salud aumente cada día más; por eso cuestionan y reclaman la versión neoliberal

\footnotetext{
${ }^{4}$ Un caso emblemático en Chile es la colusión de las farmacias; las principales cadenas farmacéuticas entre 2008 y 2009 se coludieron para alzar los precios de medicamentos.
} 
del capitalismo dominante en los últimos zo años, el cual ha generado cambios mayores en políticas, la naturaleza del trabajo, la educación, así como en valores morales y estilos de vida (Fairclough, 2010).

\section{Eje 2: de la multitud al sujeto}

A continuación, ilustramos la dimensión narrativa construida a través de tres relatos de los y las jóvenes manifestantes.

\section{Cita 1: no es un despertar solo colectivo}

Chile despertó porque se unieron muchos temas. Yo he estado muy metida en marchas feministas porque me siento llamada por la consigna que propone el feminismo y todas las problemáticas que plantea. Eso fue muy emocionante como la intervención de Las Tesis; me siento muy involucrada con eso, porque yo soy mujer y también he vivido lo que se plantea en ese canto y yo creo que Chile despertó porque todo esto ha sido como una olla de presión; porque se colmó todo con el tema del Metro y había mucha rabia acumulada. Fue una especie de pretexto, pero la verdad es que vienen muchas cosas como de antes y creo que por eso como que todo se unió y se empezó a mover gente que nunca antes se había movido. Se unió todo y creo que también fue un golpe para las vidas de las personas. No es un despertar solo colectivo sino que también hay una parte individual y siento que la vida de cada uno está cambiado. (Entrevistada mujer, 24, estudiante universitaria)

La estudiante se plantea como parte del movimiento feminista y de ahí proviene su motivación por salir a la calle y a los espacios públicos a protestar. A través de este relato nos interesa visibilizar la importancia del pensamiento y la acción feminista, junto con los movimientos de disidencia sexual, que han sido fundamentales en los últimos años en las manifestaciones y protestas sociales.

La entrevistada hace referencia específica al impacto del grupo Las Tesis. El canto «El violador eres tú», (La letra de «El violador eres tú», 2019) se hizo mundialmente conocido a partir del estallido social en Chile. Este canto interpela directamente a la manifestante, porque es algo que viven las mujeres y que ella misma ha experimentado. A través de su relato la entrevistada señala que «Chile despertó» producto de muchos temas, utilizando la metáfora de «olla a presión» para dar cuenta de la situación actual. En el fondo, plantea que las personas colapsaron, hecho que transformó el descontento en rabia acumulada producto de las injusticias e inequidades. 
Es relevante detenerse en la diferenciación que hace la entrevistada entre un despertar colectivo y un despertar individual; este último asociado a elementos más subjetivos, que dan cuenta de las transformaciones que están ocurriendo desde una subjetividad política, lo que se ilustra en la última frase de la cita: «no es solo un despertar colectivo, sino que también hay una parte individual y siento que la vida de uno está cambiando».

\section{Cita 2: si no protestamos ahora, la protesta no la va hacer nadie por nosotros}

¿Por qué salgo? Es como una reacción a este malestar que se genera al tomar conciencia de cómo funciona un poco nuestro Estado; en cómo funciona este trenzado de factores que influyen en la vida, ya sea el mercado, el Estado y también los intereses políticos que hay detrás entre quienes gobiernan. Entre quienes tienen posiciones gubernamentales y de los que están un poco detrás «manejando los hilos», como se diría. Y también porque hay un impulso generacional, siento yo, en los espacios colectivos en los que trabajo. Hay un interés de protestar, hay un interés de sacar la vozy de entender también que el momento es ahora; y si no protestamos ahora, la protesta no la va a hacer nadie por nosotros. Y también hay un efecto de masas. Si uno ve que hay una masa que sale a protestar todos los días, uno igual habita este sentimiento de masa, se identifica con esta masa y sale a protestar. Pero detrás de eso hay un profundo deseo de querer cambiar esta injusticia, de querer transformar algo a través de la protesta. (Entrevistado hombre, 21, estudiante universitario)

La cita presenta un relato que se repite entre las juventudes con las que conversamos. Señala abiertamente que salir a la calle es una reacción a un malestar asociado al tomar conciencia sobre cómo opera el poder político del país, donde se entrecruzan la noción de Estado, el mercado y la influencia que tienen las formas de gobierno en la vida social de las personas. El entrevistado señala que también sale a la calle porque hay un «impulso generacional» que se plantea como una responsabilidad individual y colectiva, basada en una dimensión temporal, que se sustenta en la idea que «si no protestamos ahora, la protesta no la va hacer nadie por nosotros».

Acá identificamos una narrativa que Sandoval y Carvallo (2019) definen como «generación sin miedo». Si bien en la cita no se mencionan las formas de actuar en la protesta, reporta la validación a su propia generación como un actor importante que tiene una responsabilidad social de sacar la voz y de un accionar concreto en el estallido social. Por otro lado, nos llama la atención cómo el entrevistado asocia el salir a la calle con un «efecto de masas». En su narrativa, damos cuenta de un discurso que se identifica con la masa, lo que, desde nuestra perspectiva, obedece a una identificación con la categoría de multitud desarrollada por Hardt y Negri. Esto asociado a la idea de pensar y sentir que el hecho 
de salir a manifestar incorpora al entrevistado a una multitud que, siendo parte de este conjunto de individualidades similares a la propia, emerge el deseo de transformar la sociedad, de superar las injusticias y «de querer transformar algo a través de la protesta».

\section{Cita 3: me siento súper interpelada por las causas}

Me siento súper interpelada por las causas, por lo que se pide, por lo que se grita. A pesar de lo peligroso y violento que se torna a veces, me siento segura; siento que estamos todos remando hacia un mismo lado y eso a uno le hace sentirse parte (...). Siempre los movimientos sociales, como por ejemplo el movimiento estudiantil, tienen la característica de pedir, de protestar en forma de reclamo y de repente con consignas claras y peticiones claras. Pero esta vez los movimientos sociales no se están quedando ahí, sino que también se está construyendo, a través de cabildos, de juntarse en las calles, de las conversaciones mismas; como que se está construyendo y pensando una nueva forma de ser. Se sabe que se está haciendo historia, se sabe que es algo que nunca había pasado antes y es lindo ser parte de eso, sentirse parte de eso. (Entrevistada mujer, 23 años, estudiante universitaria)

La entrevistada habla sobre sus motivaciones por salir a la calle y el sentido que le hace ser parte de la movilización social. Su narrativa transmite con claridad su emoción en relación a su rol social como manifestante. La joven, así como la mayoría de los jóvenes con quienes conversamos, se siente interpelada por las causas de la movilización social, en especial por las demandas y el mensaje que se transmite desde la base social. Es interesante cómo, a través de la sensación de interpelación, la entrevistada no se queda en lo discursivo, sino que su posición es performativa en relación a lo que está ocurriendo. Es decir, su posicionamiento involucra una acción que se plantea desde el cuerpo (Esteban, 2013). Si bien la entrevistada manifiesta una sensación de peligro con el hecho de salir a la calle, también señala que hay una sensación de seguridad, generándose una emoción binaria: por un lado, al sentimiento de miedo y, por otro, a un sentimiento de pertenencia, de ser parte de un colectivo que sale a la calle, es decir, de una multitud. En su narración se observa el sentido de pertenencia a algo mayor, que ella asocia a una construcción comunitaria: «por fin estamos haciendo comunidad de verdad». Por otra parte, nos permite entender algo relevante asociado al estallido social, pues a diferencia de los movimientos estudiantiles que plantearon consignas y peticiones concretas, hay un distanciamiento en términos de la dicotomía de la protesta directa centradas en un diálogo con el Estado (Vommaro, 2016). Porque como señala la joven, el movimiento actual «se está construyendo y pensando [desde] una nueva forma de ser», basadas en la generación de una nueva ciudadanía. 


\section{Discusión}

El presente estudio se pregunta sobre cómo los y las jóvenes disputan el espacio público a través de la protesta social. A partir de los resultados, son muchas las posibilidades analíticas que se pueden seguir desarrollando en relación a la participación juvenil, específicamente a través de una etnografía situada en un momento político de revuelta y transformación social.

Tomando como referencia las contribuciones teóricas de Hardt y Negri (2011) sobre el concepto de multitud, observamos que, en el caso chileno y al igual que en otras movilizaciones en distintos lugares del planeta (Hong Kong, París, Quito o Barcelona), la toma del espacio público constituye la única forma para la expresión de la protesta y la visibilización de las demandas de los colectivos juveniles (Rivera-Aguilera et al., 2019). Los llamados a romper la norma configuran el ámbito central para manifestar el descontento social y para expresiones de rebelión juvenil. En este sentido, las calles permitieron el lugar de encuentro de la multitud y, por lo tanto, ocurren acciones como la resignificación de los espacios, como es el caso de la Plaza de la Dignidad. También favorecen la destrucción de símbolos que representan la ideología que repudian; de ahí la importancia de derribar los íconos del neoliberalismo — como el Metro, las farmacias o el Retail_los cuales representan la desigualdad y la institucionalidad.

A partir de la revuelta social en Chile, consideramos que las juventudes se desprendieron de un estado narcoléptico-neoliberal ya que, sobre los escombros del capitalismo, construyeron espacios colaborativos, alejado de la política actual y del mercado. Emerge así una intencionalidad de transformar la sociedad desde la idea de colectividad, que respeta las diferencias, promueve la diversidad y propone una sociedad más justa.

Coincidimos con Ramírez (2020), en el sentido que las juventudes del siglo XXI se movilizan globalmente con intereses locales y comunitarios. En función de esto podemos concluir que el caso chileno establece una sinergia con otros movimientos juveniles, desde las siguientes premisas. En primer lugar, las nuevas generaciones se visualizan y se representan a sí mismas desde una condición de marginación y precariedad. No solo por su condición económica, social o étnica, sino por el posicionamiento que el sistema político, económico y social les ha otorgado (Ganter-Solís \& Zarzuri-Cortés, 202o; Soler-i-Martí et al., 2021; Tajerina, 2019). Tal como hemos señalado, al igual que en Cataluña (Soler-iMartí et al., 2021), Marruecos (Sánchez-García \& Touthou, 2021), Estados Unidos, Canadá 
o Turquía (Bartra, 2014), los y las jóvenes observan que su incorporación al sistema se produce desde una lógica de inclusión-excluyente (Fry, 2020; Vommaro, 2016).

En segundo lugar, la multitud produce en las sociedades españolas (Soler-i-Martí et al., 2021; Tejerina, 2019), colombianas (Aguilar-Forero, 2021), mexicanas, argentinas, brasileras (Vommaro, 2016, 2017) y chilenas (Campos-Medina, 2020) un efecto de puntapié inicial hacia la ciudadanía, que gatillan nuevas demandas sobre derechos incumplidos, necesidades y atropellos que los gobiernos producen. Así, otorgan un abanico de posibilidades a los movimientos ciudadanos para proponer cambios políticos.

En tercer lugar, los y las jóvenes, desde diversas formas demandan al Estado nuevos estilos de vida, construyendo repertorios de acción política para un apoyo mutuo y un buen vivir que apunten a subvertir la precariedad que les impone el modelo neoliberal (Ganter-Solís \& Zarzuri-Cortés, 2020; Soler-i-Martí et al., 2021; Vommaro, 2016).

A partir del 18 de octubre del 2019 en Chile, los y las jóvenes expresaron desde la rabia y la frustración su descontento con el sistema. A diferencia de las protestas de años anteriores, asociadas a los movimientos estudiantiles, las revueltas juveniles chilenas del estallido social abandonaron la lógica de la dicotomía de la protesta directa (Vommaro, 2016), dejando atrás el uso de la protesta como herramienta para plantear exigencias al Estado. Desde la multitud, comenzaron a proponer un nuevo tipo de ciudadanía, basada en un nuevo repertorio de acción política: la autoorganización como camino a una forma de construcción de democracia directa (Campos-Medina, 2020; Faure, 2020; GanterSolís \& Zarzuri-Cortés, 2020). Así, por ejemplo, el estallido social no solo posicionó demandas, sino que ejecutó acciones ciudadanas de toma de decisiones participativas, tales como cabildos o asambleas, que tuvieron como principal efecto un proceso constituyente que redactará una nueva constitución para Chile en los próximos años.

Ahora bien, la respuesta del gobierno para socavar el movimiento social se anquilosó en las históricas prácticas del orden y la represión hacia las nuevas propuestas de sociedad impulsadas por las juventudes (Jiménez-Díaz, 2018; Rivera-Aguilera et al., 2016; RiveraAguilera \& Jiménez-Díaz, 2020). Al igual que en otros países del mundo, el aparato gubernamental de acción represiva a través de las policías se materializó en asesinatos y en una serie de violaciones a los Derechos Humanos, que en Chile dejó como resultado más de 5000 detenidos, de los cuales 725 se encuentran encarcelados como presos de la revuelta (Salinas, 2020), a más de 350 personas con traumas oculares (359 heridas oculares, 2019), y 33 fallecidos (Ministerio Público registra 33 muertes durante el estallido social, 2020). Generándose de esta forma una necropolítica como consecuencia de la rebelión juvenil, 
donde el concepto de juventicidio se hace necesario como categoría analítica para futuras investigaciones (Aguilar-Forero, 2021).

Sobre los alcances del estudio, podemos destacar que la perspectiva etnográfica abordada nos permitió una proximidad con el momento social que se estaba viviendo, así como con la ciudadanía que se manifestaba en las calles. El hecho de estar con jóvenes y que, como investigadores, nos conformáramos en esa multitud, permitió una cercanía y un diálogo que generó una proximidad etnográfica con sus rabias, frustraciones y esperanzas. En términos de las limitaciones del estudio, tenemos claridad de que el abordaje teórico del tema puede ser más amplio, involucrando en mayor profundidad perspectivas feministas o decoloniales. Sabemos que los datos presentados en este artículo (fotografías, registros de conversaciones con jóvenes) pueden parecer limitados, sin embargo, dan cuenta de la toma de los espacios públicos desde una perspectiva situada.

Para cerrar, creemos que el presente artículo permite a las Ciencias Sociales abrir nuevas posibilidades teórico-metodológicas para continuar desarrollando estudios sobre revueltas juveniles, así como respecto a sus repertorios y prácticas políticas. Creemos fehacientemente que la nueva década traerá consigo nuevas expresiones de multitudes articuladas por jóvenes, quienes constituirán nuevas subjetividades políticas y otros movimientos sociales que buscarán, mediante la protesta social, transformaciones planetarias a un modelo económico que va mutando a un ritmo cambiante. En relación a esto último, analizar estos procesos de estallido y revuelta social desde la investigación cualitativa, tanto desde una perspectiva local como global, es un desafío importante que nos permitirá entender las acciones políticas de los y las jóvenes.

\section{Referencias}

359 heridas oculares: informe del INDH revela crisis de lesionados desde el inicio del estallido social. (2019, 31 de diciembre). CNN Chile. https://bit.ly/2RIfcXh Aguilar-Forero, N. (2021). Sin cuarentena: necropolítica y acción colectiva juvenil en Colombia (2020). Revista Latinoamericana de Ciencias Sociales, Niñez y Juventud, 19(1), 1-23. https://doi.org/10.1160o/rlcsnj.19.1.4539

Alvesson, M., \& Skoldberg, K. (2018). Reflexive methodology. Sage.

Andrews, J. P. (2019, 20 de octubre). Piñera: «Estamos en guerra contra un enemigo poderoso». La Tercera. https://bit.ly/307PCXz 
Bartra, A. (2014). Rejuvenecer la protesta: los movimientos sociales van a la escuela. Argumentos, $27(74), 15-44$.

Beyer, N. (2019). ¿La encarnación de una exigencia contradictoria? Algunas reflexiones en torno a la violencia policial. En K. Araujo (Ed.), Hilos tensados: para leer el octubre chileno (pp. 15-36). Universidad de Santiago de Chile.

Campos-Medina, L. (2020). ¡Evade! Reflexiones en torno a la potencia de un escrito. Universum (Talca), 35(1), 18-44. https://doi.org/10.4067/s0718-23762020000100018

De «Plaza Italia» a «Plaza de la Dignidad»: los pasos para el cambio de nombre oficial. (2019, 4 de diciembre). El Mostrador. https://bit.ly/3uDXKS5

Denzin, N., \& Lincon, Y. (2012). Manual de investigación cualitativa. Gedisa.

Eberle, T., \& Maeder, C. (2016). Organizational ethnography. En D. Silverman (Ed.), Qualitative research (pp. 121-136). Sage.

Esteban, M. (2013). Antropología del cuerpo: género, itinerarios corporales, identidad y cambio. Bellaterra.

Esteve, J. (2019). Chile y España: transiciones cuestionadas. En M. Folchi (Ed.), Chile despertó: lecturas desde la historia del estallido social de octubre. Universidad de Chile.

Faure, A. (2020). ¿Se politizó el tiempo? Ensayo sobre las batallas cronopolíticas del octubre chileno. Universum (Talca), 35(1), 46-73. https://doi.org/gb4v

Fairclough, N. (2010). Critical discourse analysis: The critical study of language. Longman. Foley, D., \& Valenzuela, A. (2012). Etnografía crítica: la política de la colaboración. En N. Denzin, \& Y. Lincon (Coords.), Manual de investigación cualitativa. Gedisa.

Frías, P., \& Garcés, M. (2019). El malestar prendió: Reflexiones sobre las experiencias de trabajo de las y los jóvenes en Chile. En K. Araujo (Ed.), Hilos tensados: para leer el octubre chileno (pp. 15-36). Universidad de Santiago de Chile.

Fry, M. (2020). Los movimientos sociales latinoamericanos: teorías críticas y debates sobre la formación. Revista de Ciencias Sociales, 33(47), 13-30. https://doi.org/gb4w

Ganter-Solís, R., \& Zarzuri-Cortés, R. (2020). Rapsodia para una revuelta social: retazos narrativos y expresiones generacionales del 18-O en el Chile actual. Universum, $35(1)$, 74-103. https://doi.org/10.4067/s0718-23762020000100074

Guber, R. (2005). El salvaje metropolitano: reconstrucción del comportamiento social en el trabajo de campo. Paidós.

Guber, R. (2011). La etnografía: método, campo y reflexividad. Siglo Veintiuno.

Hardt, M., \& Negri, A. (2011). Commonwealth: el proyecto de una revolución en común. Akal. Hardt, M., \& Negri, A. (2012). Imperio. Paidós. 
Hermansen, P., \& Fernández-Droguett, R. (2018). La foto-etnografía como metodología de investigación para el estudio de manifestaciones conmemorativas contestatarias en el espacio público. Universitas Humanística, (86), 167-196. https://doi.org/gb4x

Jiménez-Díaz, L. (2018). Memoria oficial y construcción de la paz en la postdictadura: gobernar la sociedad chilena desde las reglas de la oligarquía. En C. Palencia (Coord.), De los estados larvales a las mariposas: escenario de la razón neoliberal en América Latina. Institución Universitaria Politécnico Gran Colombiano.

Jiménez-Díaz, L. (2019). Ideologías de la transición chilena subyacentes en los discursos presidenciales de post-dictadura. Linguagem em (Dis)curso, 19(1), 49-66. https:// doi.org/10.1590/1982-4017-190104-3218

Kornblit, A. (coord.) (2004). Metodologías cualitativas en ciencias sociales: modelos y procedimientos. Biblos.

La letra de «El violador eres tú», el himno feminista que se extiende por el mundo. (2019, 8 de diciembre). El País. https://bit.ly/3ulgIKs

Martínez, J., \& Barragán, D. (2008). Juventud y multitud: aproximación para abordar los movimientos juveniles. Tabula Rasa, (9), 353-368. https://doi.org/10.25058/20112742.351

Martuccelli, D. (2019). El largo octubre chileno: bitácora sociológica. En K. Araujo (Ed.), Hilos tensados: para leer el octubre chileno (pp. 15-36). Universidad de Santiago de Chile.

Ministerio Público registra 33 muertes durante el estallido social: 4 se atribuyen a agentes del Estado. (2020, 27 de febrero). El Mostrador. https://bit.ly/2RLx2so

Papadopoulos, D. (2018). Experimental practice: Technoscience, alterontologies, and more than social movements. Duke University Press.

Pleyers, G. (2018). Movimientos sociales en el siglo XXI. Clacso.

¿Qué implica que el gobierno de Chile declare estado de emergencia? (2019, 19 de octubre). CNN Chile. https://bit.ly/3bBs7Bt

Ramírez, F. (2020). Juventud y movimientos sociales: reflexiones sobre la generación Glocal latinoamericana. Revista Argentina de Estudios de Juventud, 14, 2-18. https:// doi.org/10.24215/18524907е030

Rivera-Aguilera, G., \& Jiménez-Díaz, L. (2020). Resistance from the South: Some reflections on youth and the Chilean October. Field, (15).

Rivera-Aguilera, G., García-Quiroga, M., López-Cortés, O., Pérez-Roa, L., \& Abilio, L. C. (2019). Editorial Sección Temática: juventud, trabajo y desigualdades. Psicoperspectivas, 18(3), 1-8. https://doi.org/10.5027/psicoperspectivas-vol18-issuez-fulltext-1820 
Rivera-Aguilera, G., Morales, K., \& Pavez, J. (2016). La criminalización de los movimientos sociales: un análisis discursivo sobre la retórica que construye la ley antiencapuchados en Chile. Revista de Estudios Cotidianos, 4(1), 92-116.

Rozas-Bugueño, J., \& Somma, N. (2020). Determinantes de la protesta juvenil en Chile. Revista Mexicana de Sociología, 82(3), 673-703.

Salazar, G. (2019). El «reventón social» en Chile: una mirada histórica. Nueva Sociedad. https://nuso.org/articulo/protestas-Chile-estudiantes-neoliberalismo/

Salinas, M. (2020, diciembre 22). Indulto por estallido social: 12,75\% de detenidos está en prisión preventiva. El Dínamo. https://bit.ly/3f5 PPgI

Sánchez-García, J., \& Touhtou, R. (2021). De la Hogra al Hirak: neocolonialismo, memoria y disidencia política juvenil en el Rif. Revista Latinoamericana de Ciencias Sociales, Niñez y Juventud, 19(1), 1-2o. https://doi.org/10.116oo/rlcsnj.19.1.4591

Sandoval, J., \& Carvallo, V. (2019). Una generación «sin miedo»: Análisis de discurso de jóvenes protagonistas del movimiento estudiantil chileno. Última Década, 27(51), 225-257. https://doi.org/10.4067/so718-22362019000100225

Silva, C., \& Burgos, C. (2011). Tiempo mínimo-conocimiento suficiente: la cuasi-etnografía sociotécnica en psicología social. Psicoperspectivas, 10(2), 87-108. https://doi.org/gb43

Soler-i-Martí, R., Ballesté, E., \& Feixa, C. (2021). Desde la periferia: la noción de espacio social en la movilización sociopolítica de la juventud. Revista Latinoamericana de Ciencias Sociales, Niñez y Juventud, 19(1), 1-26. https://doi.org/10.1160o/rlcsnj.19.1.4554

Tejerina, B. (2019). Youth and precariousness in Spain: Beyond a waiting time. En E. Colombo, \& P. Rebughini (eds.), Youth and the politics of the present: Coping with complexity and ambivalence (pp. 88-100). Routledge.

Valenzuela, M. (2019). La marcha más grande de Chile: un viernes 25 de octubre de 2019 en la Plaza Italia. En K. Araujo (Ed.), Hilos tensados: para leer el octubre chileno (pp. 15-36). Universidad de Santiago de Chile.

Virno, P. (2003). La gramática de la multitud. Traficantes de Sueños.

Vommaro, P. (2016). Juventudes y políticas en la Argentina y en América Latina: tendencias, conflictos y desafíos. Grupo Editor Universitario.

Vommaro, P. (2017). Territorios y resistencias: configuraciones generacionales y procesos de politización en Argentina. Iztapalapa, Revista de Ciencias Sociales y Humanidades, 82(38), 101-133. https://doi.org/gb44 